\title{
Integrins in vascular development
}

R.O. Hynes,

B.L. Bader and

K. Hodivala-Dilke
Howard Hughes Medical Institute and Center for Cancer Research, D epartment of Biology, Massachusetts Institute of Technology, Cambridge, MA, USA

\section{Correspondence}

R.O. Hynes

Howard Hughes M edical Institute and Center for Cancer Research

Department of Biology

Massachusetts Institute of Technology

Cambridge, MA 02139

USA

Fax: + 1-617-253-8357

E-mail: rohynes@mit.edu

Presented at the 5th Brazilian

Symposium on Extracellular

Matrix - SIMEC, Angra dos Reis,

RJ, Brasil, September 7-10, 1998.

The present address of B.L. Bader is Department of Proteinchemistry,

Max-Planck-Institute for

Biochemistry, Am Klopferspitz 18a,

D-82152 Martinsried near Munich,

Germany.

Research supported by the Howard

Hughes Medical Institute and by the USPHS National Institutes of Health (grants PO 1-HL41484 and RO 1CA17007). Fellowship support was provided by the Deutsche Forschungsgemeinschaft (B.L. Bader), the Human Frontiers Science Program (K. Hodivala-Dilke) and the Dystrophic Epidermolysis Bullosa Research Association (K. Hodivala-Dilke).

Received November 11, 1998 Accepted December 14, 1998

\section{Abstract}

Many growth factors and their protein kinase receptors play a role in regulating vascular development. In addition, cell adhesion molecules, such as integrins and their ligands in the extracellular matrix, play important roles in the adhesion, migration, proliferation, survival and differentiation of the cells that form the vasculature. Some integrins are known to be regulated by angiogenic growth factors and studies with inhibitors of integrin functions and using strains of mice lacking specific integrins clearly implicate some of these molecules in vasculogenesis and angiogenesis. However, the data are incomplete and sometimes discordant and it is unclear how angiogenic growth factors and integrin-mediated adhesive events cooperate in the diverse cell biological processes involved in forming the vasculature. Consideration of the results suggests working hypotheses and raises questions for future research directions.

\section{Introduction}

The vascular system is one of the earliest organs to form during development. In mammals, both the extraembryonic vasculature in the yolk sac and the embryonic vasculature, comprising the major vessels and the primitive heart, develop soon after implantation. The processes of vascular development have commonly been divided into vasculogenesis, the generation of the vessels de novo from mesodermally derived angioblasts, and angiogenesis, the formation of vessels as sprouts or offshoots of a preexisting vascular tree (1-7). In truth the situation is much more complex. The initial yolk sac vasculature does indeed form from fusion of blood islands in a process of de novo vasculogenesis and the major vessels, such as dorsal aorta and heart, arise by aggregation of angioblasts, to give vessels where none preexist. However, the subsequent elaboration of these initial vasculatures involves produc- tion of side vessels by at least two different mechanisms; sprouting (5) and splitting (intussusception; 8-10). The resulting vascular plexuses are then remodeled to differentiate large from small vessels and arterial from venous vasculature and the endothelial tubes become variously invested with accessory cells (pericytes, smooth muscle cells, etc.). The vasculature in different organs is clearly different in many different ways. Examples such as the high endothelial venules of lymph nodes, the fenestrated endothelium of the glomerulus and the extremely tight bloodbrain barrier are well known but there exist many other variations in different organs (4).

\section{The roles of growth factors and their receptors}

How do these diverse vessel types develop? In recent years it has become clear that the cells which comprise blood vessels are regulated in their behavior by a large 
number of factors. Central among these are various growth factors; vascular endothelial growth factor (VEGF), basic fibroblast growth factor (FGF-2), TGFß, angiopoietins, neuregulin and platelet-derived growth factor (PDGF) and their corresponding receptors (5,7,11-15). FGF-2, VEGF and angiopoietins act on endothelial cells by binding to tyrosine kinase receptors, whereas PDGF and neuregulin are produced by endothelial cells and act to recruit and organize accessory cells, again by acting on tyrosine kinase receptors on those cells. The list of growth factors and receptors known to be involved in control of blood vessel development is growing fast. Potential involvement of NotchJagged signalling in angiogenesis (16) and the recent demonstration that ephrin-B2 and its counter receptor, Eph-B4, are involved in determining the distinction between venous and arterial development $(17,18)$ are two cases in point and clearly there are others to be discovered.

Various analyses, most notably those using gene ablation methods to generate mice lacking specific factors or their receptors, have provided initial insights into the roles played by these different signalling systems and a rough sequence of inductive interactions can be formulated (Figure 1; 5,7,14). Thus, VEGF, acting through two different receptors, first controls the initial determination of angioblasts and subsequently their ability to assemble into tubes. However, prior action of FGF-2 appears necessary to induce the expression of VEGF receptors in the

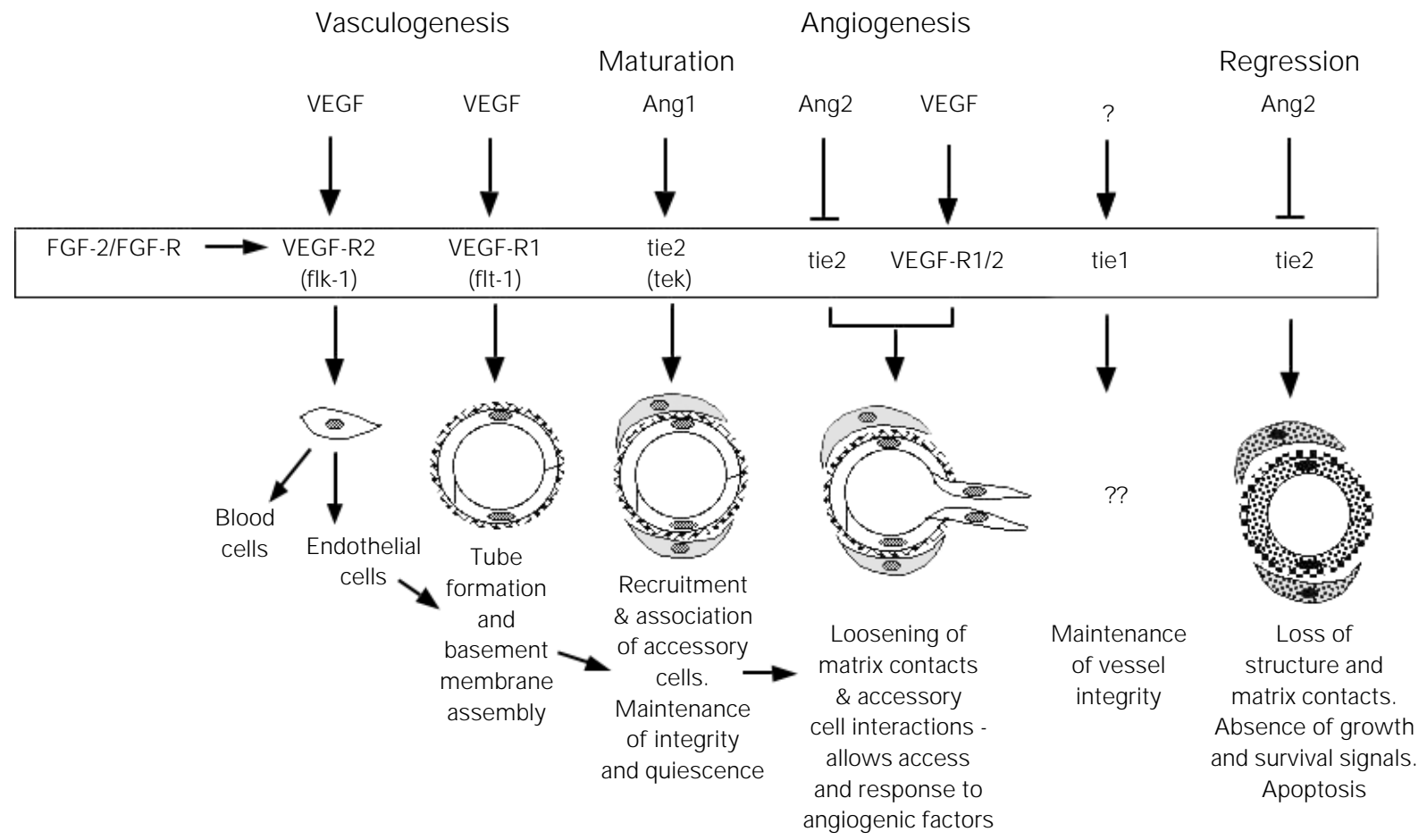

Figure 1 - Regulation of vessel formation. Diagram depicts the various phases of vascular development, the multiple growth factors impinging on endothelial cells (basic fibroblast growth factor (FGF-2), vascular endothelial growth factor (VEGF), angiopoietins) and their receptors. Factors and ligands are arranged according to the processes they affect, based on inferences drawn from the phenotypes of genetically modified mice. Thus, VEGF acting through VEGF-R2 (flk-1) affects the "birth" of endothelial cells, whereas VEGF acting through VEGF-R1 (flt-1) instead affects tube formation and VEGF collaborating with angiopoietins affects recruitment of accessory cells and angiogenesis. What is unclear, and is not shown here, is how these ligand-receptor combinations affect the morphogenetic events involving cell-matrix and cell-cell adhesion. It is in this part of these processes that integrins and their ligands may play a role (see text). Modified from an original diagram by Hanahan (14). 
endothelial precursors. Subsequently, angiopoietins acting on tie receptors affect further development of the vasculature probably including interactions between endothelial and accessory cells. PDGF, TGFß and neuregulin signaling and ephrin/Eph interactions contribute further to the differentiation of different vessel types (12,17-19).

\section{The roles of cell adhesion molecules}

This rapidly developing understanding of the hierarchy of controls affecting vascular development takes one only so far. We still need to understand how the factors and their receptor-mediated signals actually produce vessels, induce branching and endothelial-accessory cell interactions and yield the array of different vessel types found in a mature animal. At the cell biological level, these events clearly require control of cell proliferation and survival, various cell migrations and cell adhesive events, basement membrane assembly and remodeling and stable interactions between cells and with the extracellular matrices around them. Cellcell adhesion molecules such as cadherins are believed to play important roles and, indeed, gene ablation studies clearly implicate both N-cadherin (20) and VE-cadherin (21) in early steps of vessel formation. However, we will focus here on a different family of cell adhesion receptors, the integrins, and their involvement in vascular development and remodeling.

Integrins are a family of heterodimeric cell surface receptors, which mediate adhesion of cells to extracellular matrix proteins and sometimes to other cells (22). In mammals, around two dozen integrins are known and endothelial cells can express at least five or six different ones (23). Cell surface expression of integrins can be controlled by various growth factors, including, notably, VEGF (see below). In addition to mediating cell adhesion to, and cell migration on, a variety of extracellular matrix molecules rel- evant to vascular development (fibronectin (FN), collagens, laminins, vitronectin, von Willebrand factor, thrombospondin, osteopontin, fibrinogen, entactin/nidogen), integrins also mediate intracellular signalling events involving various protein kinases, small GTPases, etc. (24-28) and these in turn control aspects of cytoskeletal organization and cell motility (29-31), and also regulate cell cycle progression, apoptosis and gene expression $(32,33)$. Therefore, integrins occupy a central position in any consideration of vascular development; they are regulated by growth factors known to control the process, they mediate exactly those cell biological processes (adhesion, migration, proliferation, survival and differentiation) needed to organize a vasculature and they are expressed by the cells involved (endothelial cells, pericytes, smooth muscle cells). There is, in fact, a large and growing body of evidence implicating various integrins and integrin ligands in vascular development (23,34-36). However, it is not clear exactly which integrins are the most important nor exactly what each of them does. In this brief article, we will review the relevant results (Table 1) and discuss the many unresolved questions.

One major body of work bearing on the possible roles of integrins in vasculogenesis and angiogenesis involves the use of blocking reagents (antibodies, peptides, peptidomimetics) to inhibit the functions of various integrins. This approach has been used most intensively to investigate the functions of $\alpha \mathrm{v}$ integrins. These represent a subset of the integrin family sharing a common $\alpha v$ subunit in combination with one of five different $\beta$ subunits ( $\beta 1, \beta 3, \beta 5, \beta 6, \beta 8)$. Endothelial cells can express at least $\alpha v \beta 3$ and $\alpha v \beta 5$ and perhaps $\alpha \mathrm{v} \beta 1$ (since they do express B1), although resting endothelial cells express little or no $\alpha \mathrm{v} \beta 3(34,35)$. However, this integrin is markedly upregulated on vessels undergoing angiogenesis (37-39). Cheresh and his colleagues (40) have shown 
that monoclonal antibodies or peptides that selectively bind $\alpha v \beta 3$ or $\alpha v \beta 5$ can inhibit vasculogenesis during early quail embryo development and angiogenesis in the chicken chorioallantoic membrane (CAM) both during normal development (37) and in response to FGF-2 or VEGF $(37,39)$ or tumor implants $(37,41)$. They have also shown inhibition of angiogenesis in response to tumor implants on human skin transplants to mice (38) and during neovascularization in the murine retina (39) and another group has provided corroborative data in the latter system (42). Cheresh and colleagues (43) have further shown that different angiogenic stimuli apparently rely on either $\alpha v \beta 3$ (FGF2, TNF $\alpha$ ) or $\alpha \mathrm{v} B 5$ (VEGF, phorbol esters) and have shown that $\alpha v \beta 3$ can bind the matrix metalloprotease (MMP-2) in a fashion that contributes to an invasive response and to angiogenesis $(44,45)$. These results have stimulated a lot of interest, not least because of the potential use of blocking reagents for therapy of a variety of disorders including tumor angiogenesis and blindness caused by retinal neovascularization.

Senger et al. (46) have reported similar antiangiogenic responses using antibodies directed against $\alpha 1 \beta 1$ and $\alpha 2 \beta 1$ integrins, which are also markedly upregulated by VEGF. Furthermore, Drake et al. (47) had earlier shown that antibodies to avian $B 1$ integrin interfere with dorsal aorta vasculogenesis. These results suggest that integrins other than $\alpha v$ integrins play significant roles in vascular development.

Results on mouse strains lacking specific integrins also implicate several different integrins in vasculogenesis and angiogenesis (see Table 1). Ablation of $\alpha 5 \beta 1$ integrin (48) or its ligand, fibronectin $(49,50)$, causes major disruptions in development of extraem-

Table 1 - Integrins and their ligands in vascular development.

VEGF, Vascular endothelial growth factor; FGF-2, basic fibroblast growth factor; VCAM-1, vascular cell adhesion molecule.

\begin{tabular}{|c|c|c|c|}
\hline Integrin & Ligands & Observations & References \\
\hline$\alpha 1 ß 1$ & Collagens & - Induced by VEGF & 46 \\
\hline \multirow[t]{3}{*}{$\alpha 2 ß 1$} & Laminins & - Antibodies to those integrins block VEGF-induced angiogenesis in mouse skin & \\
\hline & & - $\alpha 1$ knockout; viable; $\alpha 2$ knockout, not done & 52 \\
\hline & & $-\alpha 1 ß 1$ is upregulated after vascular injury & 68 \\
\hline \multirow[t]{2}{*}{$\alpha 4 ß 1$} & Fibronectin & - $\alpha 4$ knockout and VCAM-1 knockout show defects & $69-71$ \\
\hline & VCAM-1 & in formation of coronary vessels & \\
\hline \multirow[t]{3}{*}{$\alpha 5 ß 1$} & Fibronectin & - Antibodies to ß1 integrins block vasculogenesis in quail embryo & 47 \\
\hline & & - $\alpha 5$ knockout shows defective vasculogenesis in yolk sac and embryo & 48 \\
\hline & & - FN knockout shows even more severe defects in vasculogenesis & 49,50 \\
\hline \multirow{7}{*}{$\begin{array}{l}\alpha \mathrm{V} ß 3 \\
\alpha \mathrm{V} ß 5 \\
\alpha \mathrm{V} ß 1\end{array}$} & Vitronectin & - Induced by VEGF, FGF-2, etc. & $37,38,41,45$ \\
\hline & Fibrinogen & - Antibodies and peptides block angiogenesis at many & 43 \\
\hline & Osteopontin & sites in response to VEGF, FGF-2, tumors, etc. & \\
\hline & Thrombospondin & - Antibodies and peptides block vasculogenesis in quail embryo & 40 \\
\hline & von Willebrand factor & - Retinal neovascularization is also inhibited by such agents & 39,42 \\
\hline & Plus others (see text) & $\begin{array}{l}\text { - } \alpha v \text { knockout shows extensive vasculogenesis and angiogenesis, } \\
\text { although cerebral vasculature is defective }\end{array}$ & 53 \\
\hline & & - ß3 knockout shows normal vascular development including retinal vessels & 59 \\
\hline Other integrins & Other ligands & $\begin{array}{l}\text { - Many other knockouts of integrins or their ligands show } \\
\text { no evidence of crucial involvement in vascular development, } \\
\text { although further work is necessary }\end{array}$ & 36,72 \\
\hline
\end{tabular}


bryonic (yolk sac) and embryonic (heart, aorta) vasculature. In both cases, endothelial cells do differentiate, that is, the VEGF/ VEGF-R2-mediated induction of angioblasts is intact. However, absence of either $\alpha 5 \beta 1$ or fibronectin disrupts vessel formation in a fashion somewhat reminiscent of the defects seen in embryos lacking VEGF-R1 (flt-1; 51). Clearly interactions of endothelial cells with FN play an important role in these early steps and there exists a distinct possibility that there is regulation of $\alpha 5 \beta 1$ expression or function by VEGF/VEGF-R1 or that this signalling system cooperates with the $\alpha 5 \beta 1$ FN-regulated responses. This result conforms with the inhibition of early vascular development by anti- $\beta 1$ antibodies (47).

In contrast with this concordance between antibody blocking and genetic ablation results, some other studies show less convergence. Although antibody blockade of $\alpha 1 \beta 1$ and $\alpha 2 \beta 1$ integrins blocks angiogenesis in the CAM (46), ablation of the $\alpha 1$ gene yields viable, fertile animals with no evidence of vascular defects (52). Since $\alpha 1 \beta 1$ and $\alpha 2 \beta 1$ both act as collagen and laminin receptors, it is possible that they serve overlapping and to some extent redundant roles. Unfortunately the $\alpha 2$-knockout is not yet available. Time will tell whether there is indeed a conflict here between the immunological and genetic approaches. However, it is already clear that ablation of the $\alpha \mathrm{v}$ integrin gene yields results that are difficult to reconcile with the results of $\alpha \mathrm{v}$-inhibitors (53). $\alpha \mathrm{v}$-null mouse embryos develop an apparently normal yolk sac and early embryonic vasculature (53) in marked contrast with the blockade of quail dorsal aorta formation (40) or chicken chorioallantoic angiogenesis (37) by antibodies directed against $\alpha v \beta 3$. Granted that the systems employed in these studies are different, the two sets of data differ greatly in their implications for the importance of $\alpha$ v integrins in early vascular development. Indeed, $20 \%$ of $\alpha \mathrm{v}$-null embryos develop to term and are born alive, although they die promptly (53). There is extensive vasculogenesis and angiogenesis in most organs and tissues in the absence of all five $\alpha v$ integrins. Although $\alpha v$-null embryos consistently develop defects in their brain vasculature, the basic endothelial processes of proliferation, migration, tube formation and branching, and basement membrane assembly all occur. Furthermore, there is no evidence for increased apoptosis of $\alpha \mathrm{v}$ null endothelial cells in contrast with the effects of blockade of $\alpha \mathrm{v}$-integrins by antibodies or peptides (41). Again, the vascular systems under study are different but clearly the implications of the results differ significantly.

The intracerebral vasculature in $\alpha v$-null embryos is not normal; it becomes distended and eventually ruptures leading to cerebral hemorrhage (53). This result is somewhat reminiscent of the defects occurring in PDGFB-null embryos, which are thought to be due to failure of immigration of pericytes along the cerebral vessels (54), raising the possibility that the $\alpha v$-null defect arises from a failure in pericyte recruitment to the vessels. However, the $\alpha v$-null defects initiate rather too early for this to be the sole cause and it remains to be discovered what exactly are the $\alpha v$-dependent processes unique to this vascular bed. Vascular defects in angiopoietin- 1 or tie 2 knockout mice $(19,55,56)$ also show some resemblances to those in $\alpha \mathrm{v}$-null and PDGF-B-null embryos raising the possibility that these various genes may cooperate somehow in the assembly of a normal vasculature.

Since the $\alpha v$-null animals die during gestation or at birth (53) it has not yet been possible to analyze the effects of $\alpha \mathrm{v}$ integrin ablation on later angiogenesis such as that in the retina or in response to tumors. However, viable knockout mice lacking each of three of the $\alpha v$-associated $\beta$ subunits $(\beta 3, \beta 5, \beta 6)$ do exist (57; Huang XZ and Sheppard D, personal communication, and 58, respectively). In all three cases the animals are 
viable and fertile and show no obvious defects in their vascular development. However, much remains to be investigated and it is possible that further analyses of these null strains, or of double mutants generated from them, may reveal dependence of angiogenesis on one or more of these integrins, as might be expected from the $\alpha v$ inhibition data. To date, the B3-null mice have been investigated for defects in postnatal retinal angiogenesis and there are no major defects (59). However, the effects of perturbations such as hyperoxia or hypoxia or of combinations of $\beta$-mutations have yet to be studied and these mice should prove very useful both for such studies and for analyses of angiogenesis after wound healing, in response to tumors, etc.

The apparent discrepancy between the antibody and peptide blocking data and the genetic analyses of $\alpha \mathrm{v}$ integrins is enhanced by consideration of the phenotypes of mice lacking individual extracellular matrix proteins that are ligands for $\alpha v$ integrins. Apart from the embryonic lethal phenotype of FNnull embryos $(49,50)$ which is most likely a consequence of its interactions with $\alpha 5 \beta 1$ $(48,60)$, most other mouse strains lacking $\alpha \mathrm{v}$ integrin ligands are viable and fertile and have, so far, shown no evidence of vascular defects, although, as for the $\beta$ integrin-null mice discussed above, more detailed analyses are needed. Nonetheless, it is striking that mice lacking vitronectin (61), tenascinC (62), osteopontin (63), fibrinogen (64) von Willebrand factor (65) or thrombospondin-1 (66) are all viable.

What is one to make of the apparent discrepancies between genetics and inhibition studies? As we have noted, some of the discrepancies may simply reflect the fact that inferences are being drawn from somewhat different systems, in which case further analyses may show that the initial discrepancies are apparent rather than real. However, it is also possible that the two different ap- proaches will continue to yield discordant results. How could this be so? One possibility is that the genetic ablations underestimate contributions of a given integrin or matrix molecule either because of overlapping functions of another gene or molecule or because, in its absence, the organism compensates for the missing component by expressing or utilizing a component which normally does not play a role. Such compensation has been observed in some knockout strains, although it is more often invoked than demonstrated. However, in the final analysis, it is difficult to rule out and must be considered. An equally likely possibility is that the intervention experiments overestimate the contributions of a given component. Leaving aside the more trivial possibilities of cross reaction of blocking antibodies or peptides with other components, there is also the more subtle possibility of transdominant inhibition, even by truly selective reagents. It has clearly been shown that selective inhibition of one integrin on a cell can have inhibitory effects on other integrins in the same cell (67). The mechanism is unclear at present, although a plausible possibility is that integrins compete for some limiting components within the cell (e.g., a cytoskeletal or signal transduction molecule) and that engagement of one integrin by a selective binding inhibitor depletes the supply of the limiting component with consequent trans-inhibition of other integrins. Other mechanisms could include inter-integrin regulation which is known to occur in a number of situations $(22,57)$. In the absence of further analyses to decide between the two different approaches (genetic, and immunological/pharmacological) one must draw inferences about the relative importance of different constituents with caution. In the case of integrins, their ligands and vascular development, several are implicated but their relative importance in different vascular responses remains unclear. 


\section{Conclusions and future prospects}

So the current situation is as follows (Figure 2). We know of a variety of growth factors and receptors which are clearly implicated in controlling vasculogenesis and angiogenesis (Figure 1), although exactly what they all do is not yet clear. Most particularly we do not know how they do what they do; that is, what are the intermediate molecules which they control? That is where integrins and their ligands come in. Some of these molecules clearly are regulated by VEGF and the like; others may be as well.
Integrins and their ligands clearly do play important roles in the cell biological subroutines necessary for vessel development (adhesion, migration, proliferation, survival, differentiation, matrix formation) but it is unclear exactly which ones are most important in the different processes. Indeed the answers to those questions may differ depending on the vascular bed or the angiogenic stimulus. It may well be, indeed it seems likely, that there is more than one form of angiogenesis. It could be that yolk sac vasculature relies primarily on $\alpha 5 \beta 1-\mathrm{FN}$ interactions and less, or not at all, on $\alpha$ integrins,

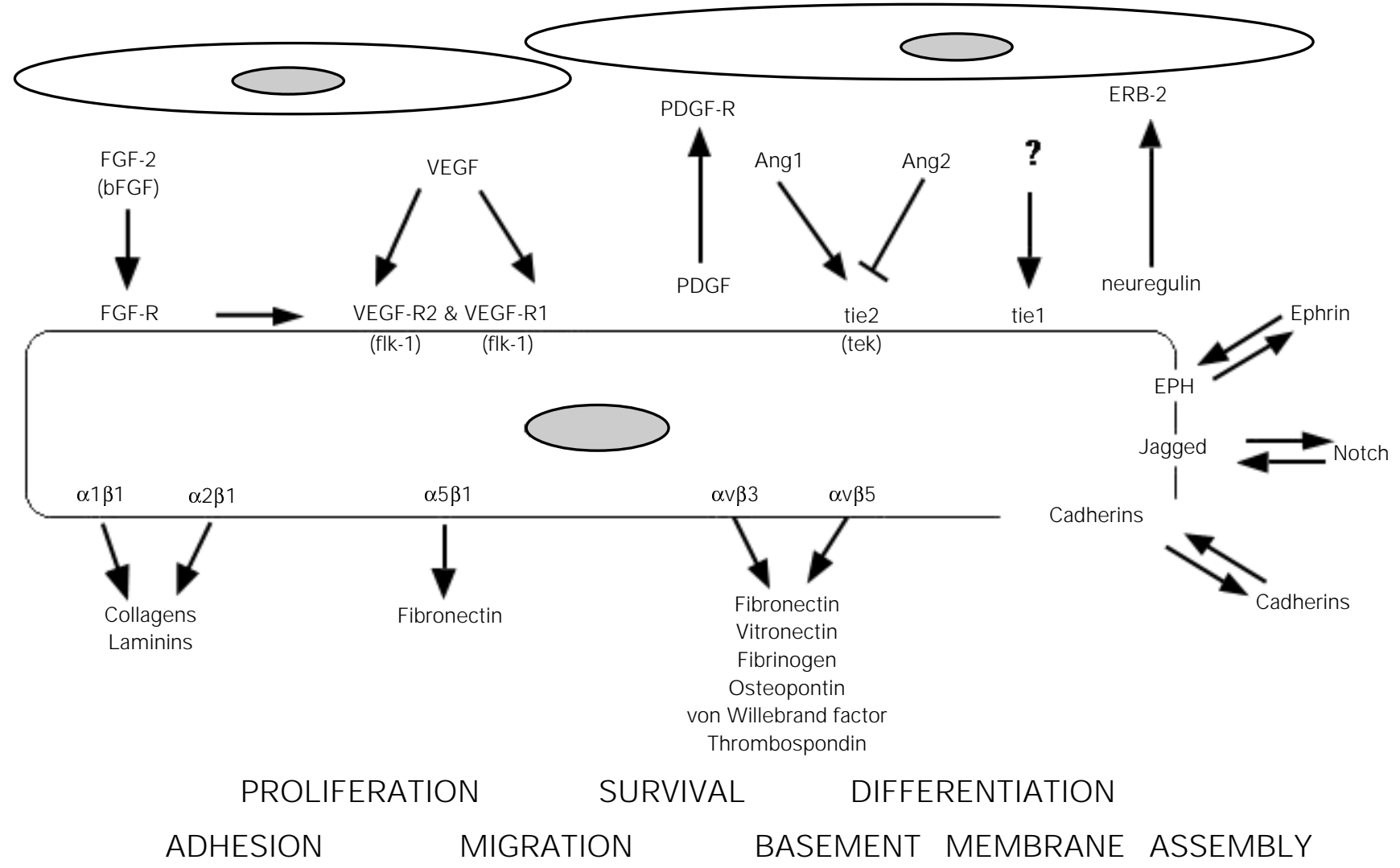

Figure 2 - Interplay of growth factor-receptor signals and cell adhesion receptors. The figure depicts an endothelial cell in the center, expressing various integrins (whose major ligands are noted), which are implicated in one or more aspects of vasculogenesis or angiogenesis (see text) and receptors for basic fibroblast growth factor (FGF-2), vascular endothelial growth factor (VEGF), and angiopoietins. The latter are produced by various cells in the vicinity of developing vessels and those cells in turn receive stimulation by factors secreted by the endothelial cells (e.g., platelet-derived growth factor (PDGF) and neuregulin) that act on receptors on the accessory cells. The latter cells also express and use integrins (data not shown). Thus, there is a two-way "conversation" between endothelial cells and their neighbors and adhesion events involving either or both. Also shown are interactions involving eph/ephrin family members, the Notch pathway and cadherins (see text). At the bottom are shown various cell biological events which must be appropriately controlled to yield vessels of different types. The challenge is to define the interplay among the various receptors and ligands and the contributions made by each to the cell biology of vasculogenesis and angiogenesis. 
whereas retinal or tumor vasculatures may be more dependent on $\alpha \mathrm{v}$ integrins and their ligands. More detailed studies of the expression patterns, regulation and functions of different integrins and their ligands in response to different angiogenic growth factors are clearly necessary. Vessel development and remodeling involve multiple cell biological processes that need to be well coordinated to yield a functional vasculature. It stands to reason that such a complex process, involving as it does, several differ- ent cell types acting in concert, would require regulation by multiple adhesive proteins. It will be a fascinating challenge to unravel the regulatory networks and coordinated functions of all these players (Figure 2 ). The potential yield from a detailed understanding of these processes is significant both in terms of the underlying biology and in terms of opportunities for intervention in diseases involving dysregulation of vessel growth.

\section{References}

1. Noden DM (1989). Embryonic origins and assembly of blood vessels. American Reviews of Respiratory Disease, 140: 10971103.

2. Folkman J \& Shing Y (1992). Angiogenesis. J ournal of Biological Chemistry, 267: 10931-10934.

3. Risau W (1991). Vasculogenesis, angiogenesis and endothelial cell differentiation. In: Feinberg RN, Sherer GK \& Auerbach R (Editors), The Development of the Vascular System. Issues in Biomedicine, 14: 58-68.

4. Risau W (1995). Differentiation of endothelium. FASEB J ournal, 9: 926-933.

5. Risau W (1997). Mechanisms of angiogenesis. Nature, 386: 671-674.

6. Risau W \& Flamme I (1995). Vasculogenesis. Annual Reviews of Cell and Developmental Biology, 11: 73-91.

7. Beck J r L \& D'Amore PA (1997). Vascular development: cellular and molecular regulation. FASEB J ournal, 11: 365-373.

8. Patan S, Haenni B \& Burri PH (1996). Implementation of intussusceptive microvascular growth in the chicken chorioallantoic membrane (CAM). 1. Pillar formation by folding of the capillary wall. Microvascular Research, 51: 80-98.

9. Patan S, Munn LL \& J ain RK (1996). Intussusceptive microvascular growth in a human colon adenocarcinoma xenograft: a novel mechanism of tumor angiogenesis. Microvascular Research, 51: 260-272.

10. Patan S, Haenni B \& Burri PH (1997). Implementation of intussusceptive microvascular growth in the chicken chorioallantoic membrane (CAM). 2. Pillar formation by capillary fusion. Microvascular Research, 53: 33-52.

11. Mustonen T\& Alitalo K (1995). Endotheli- al receptor tyrosine kinases involved in angiogenesis. J ournal of Cell Biology, 129: 895-898.

12. Folkman J \& D'Amore PA (1996). Blood vessel formation: what is its molecular basis? Cell, 87: 1153-1155.

13. Breier G\& Risau W (1996). The role of vascular endothelial growth factor in blood vessel formation. Trends in Cell Biology, 6: 454-456.

14. Hanahan D (1997). Signaling vascular morphogenesis and maintenance. Science, 277: 48-50.

15. Korpelainen EI \& Alitalo K (1998). Signaling angiogenesis and lymphangiogenesis. Current Opinion in Cell Biology, 10: 159164.

16. Zimrin AB, Pepper MS, McMahon GA, Nguyen $F$, Montesano $R \&$ Maciag $T$ (1996). An antisense oligonucleotide to the Notch ligand J agged enhances fibroblast growth factor-induced angiogenesis in vitro. J ournal of Biological Chemistry, 271: 32499-32502.

17. Wang HU, Chen ZF \& Anderson DJ (1998). Molecular distinction and angiogenic interaction between embryonic arteries and veins revealed by ephrin-B2 and its receptor Eph-B4. Cell, 93: 741753.

18. Yancopoulos GD, Klagsbrun $M \&$ \& Folkman J (1998). Vasculogenesis, angiogenesis, and growth factors: ephrins enter the fray at the border. Cell, 93: 661-664.

19. Radice $G$, Rayburn $H$, Matsunami $H$, Knudsen KA, Takeichi $M$ \& Hynes RO (1997). Developmental defects in mouse embryos lacking $\mathrm{N}$-cadherin. Developmental Biology, 181: 64-78.

20. Suri $C$, J ones PF, Patan S, Bartunkova $S$, Maisonpierre PC, Davis S, Sato TN \&
Yancopoulos GD (1996). Requisite role of angiopoietin-1, a ligand for the TIE2 receptor, during embryonic angiogenesis. Cell, 87: 1171-1180.

21. Vittet D, Buchou T, Scheitzer A, Dejana E \& Huber P (1997). Targeted null-mutation in the vascular endothelial-cadherin gene impairs the organization of vascular-like structures in embryoid bodies. Proceedings of the National Academy of Sciences, USA, 94: 6273-6278.

22. Hynes RO (1992). Integrins: versatility, modulation, and signaling in cell adhesion. Cell, 69: 11-25.

23. Luscinskas FW \& Lawler J (1994). Integrins as dynamic regulators of vascular function. FASEB J ournal, 8: 929-938.

24. Clark EA \& Brugge J S (1995). Integrins and signal transduction pathways: the road taken. Science, 268: 233-239.

25. Schwartz MA, Schaller MD \& Ginsberg $\mathrm{MH}$ (1995). Integrins: emerging paradigms of signal transduction. Annual Reviews of Cell and Developmental Biology, 11: 549-599.

26. Yamada KM \& Miyamoto S (1995). Integrin transmembrane signaling and cytoskeletal control. Current Opinion in Cell Biology, 7: 681-689.

27. Clark EA \& Hynes RO (1997). Meeting report. 1997 Keystone Symposium on Signal Transduction by Cell Adhesion Receptors. BBA Reviews on Cancer, 1333: R9R16.

28. Giancotti FG (1997). Integrin signaling: specificity and control of cell survival and cell cycle progression. Current Opinion in Cell Biology, 9: 691-700.

29. Burridge $K \&$ Chrzanowska-Wodnicka M (1996). Focal adhesions, contractility and signaling. Annual Review of Cell and De- 
velopmental Biology, 12: 463-518.

30. Huttenlocher A, Sandborg RR \& Horwitz AF (1995). Adhesion in cell migration, 7: 697-706.

31. Lauffenburger DA \& Horwitz AF (1996). Cell migration: a physically integrated molecular process. Cell, 84: 359-369.

32. Assoian RK (1997). Anchorage-dependent cell cycle progression. J ournal of Cell Biology, 136: 1-4.

33. Frisch SM \& Ruoslahti E (1997). Integrins and anoikis. Current Opinion in Cell Biology, 9: 701-706.

34. Varner J A, Brooks PC \& Cheresh DA (1995). The integrin alpha $V$ beta 3: angiogenesis and apoptosis. Cell Adhesion and Communication, 3: 367-374.

35. Strömblad S \& Cheresh DA (1996). Cell adhesion and angiogenesis. Trends in Cell Biology, 6: 462-468.

36. Hynes RO \& Bader BL (1997). Targeted mutations in integrins and their ligands: their implications for vascular biology. Thrombosis and Haemostasis, 78: 83-87.

37. Brooks PC, Clark RA \& Cheresh DA (1994). Requirement of vascular integrin alpha $v$ beta 3 for angiogenesis. Science, 264: 569-571.

38. Brooks PC, Stromblad S, Klemke R, Visscher D, Sarkar FH \& Cheresh DA (1995). Antiintegrin alpha $v$ beta 3 blocks human breast cancer growth and angiogenesis in human skin. J ournal of Clinical Investigation, 96: 1815-1822.

39. Friedlander $M$, Theesfeld $C L$, Sugita $M$, Fruttiger $M$, Thomas MA, Chang $S \&$ Cheresh DA (1996). Involvement of integrins alpha $v$ beta 3 and alpha $v$ beta 5 in ocular neovascular diseases. Proceedings of the National Academy of Sciences, USA, 93: 9764-9769.

40. Drake CJ , Cheresh DA \& Little CD (1995). An antagonist of integrin alpha $v$ beta 3 prevents maturation of blood vessels during embryonic neovascularization. J ournal of Cell Science, 108: 2655-2661.

41. Brooks PC, Montgomery AM, Rosenfeld M, Reisfeld RA, Hu T, Klier G \& Cheresh DA (1994). Integrin alpha $v$ beta 3 antagonists promote tumor regression by inducing apoptosis of angiogenic blood vessels. Cell, 79: 1157-1164.

42. Hammes HP, Brownlee M, J onczyk A, Sutter A \& Preissner KT (1996). Subcutaneous injection of a cyclic peptide antagonist of vitronectin receptor-type integrins inhibits retinal neovascularization. Nature Medicine, 2: 529-533.

43. Friedlander $M$, Brooks PC, Shaffer RW, Kincaid CM, Varner JA \& Cheresh DA (1995). Definition of two angiogenic path- ways by distinct alpha $v$ integrins. Science, 270: 1500-1502.

44. Brooks PC, Stromblad S, Sanders LC, von Schalscha TL, Aimes RT, StetlerStevenson WG, Quigley JP \& Cheresh DA (1996). Localization of matrix metalloproteinase MMP-2 to the surface of invasive cells by interaction with integrin alpha v beta 3. Cell, 85: 683-693.

45. Brooks PC, Silletti S, von Schalscha TL, Friedlander M \& Cheresh DA (1998). Disruption of angiogenesis by PEX, a noncatalytic metalloproteinase fragment with integrin binding activity. Cell, 92: 391-400.

46. Senger DR, Claffey KP, Benes J E, Perruzzi CA, Sergiou AP \& Detmar M (1997). Angiogenesis promoted by vascular endothelial growth factor: regulation through alphalbetal and alpha2betal integrins. Proceedings of the National Academy of Sciences, USA, 94: 13612-13617.

47. Drake CJ, Davis LA \& Little CD (1992). Antibodies to ß1-integrins cause alterations of aortic vasculogenesis, in vivo. Developmental Dynamics, 193: 83-91.

48. Yang J T, Rayburn H \& Hynes RO (1993). Embryonic mesodermal defects in alpha 5 integrin-deficient mice. Development, 119: 1093-1105.

49. George EL, Georges-Labouesse EN, Patel-King RS, Rayburn H \& Hynes RO (1993). Defects in mesoderm, neural tube and vascular development in mouse embryos lacking fibronectin. Development, 119: 1079-1091.

50. George EL, Baldwin HS \& Hynes RO (1997). Fibronectins are essential for heart and blood vessel morphogenesis but are dispensable for initial specification of precursor cells. Blood, 90: 3073-3081.

51. Fong GH, Rossant J, Gertsenstein M \& Breitman ML (1995). Role of the Flt-1 receptor tyrosine kinase in regulating the assembly of vascular endothelium. Nature, 376: 66-70.

52. Gardner H, Kreidberg J, Koteliansky V \& J aenisch R (1996). Deletion of integrin $\alpha 1$ by homologous recombination permits normal murine development but gives rise to a specific deficit in cell adhesion. Developmental Biology, 175: 301-313.

53. Bader BL, Rayburn H, Crowley D \& Hynes RO (1998). Extensive vasculogenesis, angiogenesis and organogenesis precede lethality in mice lacking all $\alpha v$ integrins. Cell (in press).

54. Lindahl $\mathrm{P}$, J ohansson $\mathrm{BR}$, Leveen $\mathrm{P} \&$ \& Betsholtz C (1997). Pericyte loss and microaneurysm formation in PDGF-B-deficient mice. Science, 277: 242-245.

55. Dumont DJ , Gradwohl G, Fong GH, Puri
MC, Gertsenstein M, Auerbach A \& Breitman ML (1994). Dominant-negative and targeted null mutations in the endothelial receptor tyrosine kinase, tek, reveal a critical role in vasculogenesis of the embryo. Genes and Development, 8: 1897-1909.

56. Sato TN, Tozawa Y, Deutsch U, WolburgBuchholz K, Fujiwara Y, Gendron-Maguire M, Gridley T, Wolburg H, Risau W \& Qin Y (1995). Distinct roles of the receptor tyrosine kinases Tie- 1 and Tie- 2 in blood vessel formation. Nature, 376: 70-74.

57. Hodivala-Dilke KM, DiPersio CM, Kreidberg J A \& Hynes RO (1998). Novel roles for $\alpha 3 ß 1$ integrin as a regulator of cytoskeletal assembly and as a transdominant inhibitor of integrin receptor function in mouse keratinocytes. Journal of Cell Biology, 142: 1357-1369.

58. Huang XZ, Wu J F, Cass D, Erle DJ , Corry D, Young SG, Farese J r RV \& Sheppard D (1996). Inactivation of the integrin beta 6 subunit gene reveals a role of epithelial integrins in regulating inflammation in the lung and skin. J ournal of Cell Biology, 133: 921-928.

59. Hodivala-Dilke KM, McHugh $\mathrm{K}$, Tsakiris DA, Rayburn H, Crowley D, UllmanCulleré $M$, Ross FP, Coller BS, Teitelbaum $S \&$ Hynes RO (1999). B3-integrin-deficient mice: a model for Glanzmann thrombasthenia showing placental defects and reduced survival. J ournal of Clinical Investigation (in press).

60. Goh KL, Yang JT \& Hynes RO (1997). Mesodermal defects and cranial neural crest apoptosis in alpha5 integrin-null embryos. Development, 124: 4309-4319.

61. Zheng X, Saunders TL, Camper SA, Samuelson LC \& Ginsburg D (1995). Vitronectin is not essential for normal mammalian development and fertility. Proceedings of the National Academy of Sciences, USA, 92: 12426-12430.

62. Saga $Y$, Yagi $T$, Ikawa $Y$, Sakakura $T \&$ Aizawa S (1992). Mice develop normally without tenascin. Genes and Development, 6: 1821-1831.

63. Liaw L, Birk DE, Ballas CB, Whitsitt J , Davidson J M \& Hogan BLM (1998). Altered wound healing in mice lacking a functional osteopontin gene (spp1). J ournal of Clinical Investigation, 101: 14681478.

64. Suh TT, Holmbäck $K$, J ensen NJ, Daughterty CC, Small K, Simon DI, Potter SS \& Degen JL (1995). Resolution of spontaneous bleeding events but failure of pregnancy in fibrinogen-deficient mice. Genes and Development, 9: 2020-2033. 
65. Denis CC, Methia N, Frenette PS, Rayburn $\mathrm{H}$, Ullman-Culleré $M$, Hynes RO \& Wagner DD (1998). A mouse model of severe von Willebrand disease: defects in hemostasis and thrombosis. Proceedings of the National Academy of Sciences, USA, 95: 9524-9529.

66. Lawler J, Sunday M, Thibert V, Duquette M, George EL, Rayburn $\mathrm{H} \&$ Hynes RO (1998). Thrombospondin-1 is required for normal murine pulmonary homeostasis and its absence causes pneumonia. J ournal of Clinical Investigation, 101: 982-992.

67. Diaz-Gonzalez F, Forsyth J, Steiner B \& Ginsberg MH (1996). Transdominant inhi- bition of integrin function. Molecular Biology of the Cell, 7: 1939-1951.

68. Gotwals PJ , Chi-Rosso G, Lindner V, Yang J, Ling L, Fawell SE \& Koteliansky VE (1996). The $\alpha 1 ß 1$ integrin is expressed during neointima formation in rat arteries and mediates collagen matrix reorganization. J ournal of Clinical Investigation, 97: 2469-2477.

69. Yang J T, Rayburn H \& Hynes RO (1995). Cell adhesion events mediated by alpha 4 integrins are essential in placental and cardiac development. Development, 121: 549-560.

70. Kwee L, Baldwin S, Stewart CS, Buck C \&
Labow MA (1995). Defective development of the embryonic and extraembryonic circulatory systems in vascular cell adhesion molecule (VCAM-1) deficient mice. Development, 121: 489-503.

71. Gurtner GC, Davis V, Li H, McCoy MJ, Sharp A \& Cybulsky MI (1995). Targeted disruption of the murine VCAM-1 gene: essential role of VCAM-1 in chorioallantoic fusion and placentation. Genes and Development, 9: 1-14.

72. Hynes RO (1996). Targeted mutations in cell adhesion genes: what have we learned from them? Developmental Biology, 180: 402-412. 